
\title{
R Research S Suare \\ Climate change and Forest disturbances in Europe: an economic analysis of the losses
}

\author{
Jose-Maria Da-Rocha \\ Universidade de Vigo \\ Javier Garcia-Cutrin \\ Universidade de Vigo \\ Jaume Sempere ( $\nabla$ jsempe@colmex.mx ) \\ El Colegio de México

\section{Maria-Jose Gutierrez} \\ University of the Basque Country \\ Maria-Luisa Chas-Amil \\ Universidade de Santiago de Compostela \\ Eduardo Sanchez-Llamas \\ Universidade de Santiago de Compostela
}

\section{Article}

Keywords: Climate warming, Forestry disturbances, (DICE)models, FIGARO input-output

Posted Date: January 19th, 2021

DOI: https://doi.org/10.21203/rs.3.rs-144593/v2

License: (c) (i) This work is licensed under a Creative Commons Attribution 4.0 International License.

Read Full License 


\title{
Climate change and Forest disturbances in Europe: an economic analysis of the losses
}

\author{
José-María Da-Rocha ${ }^{1,+*}$, Javier Garcia-Cutrín ${ }^{1,+}$, Jaume Sempere ${ }^{2,+}$, María-José \\ Gutiérrez $^{3,+}$, María-Luisa Chas-Amil ${ }^{4,+}$, and Eduardo Sánchez-Llamas ${ }^{4,+}$ \\ ${ }^{1}$ Universidade de Vigo, ECOBAS, Vigo,36310, Spain. \\ ${ }^{2}$ El Colegio de México, CDMx, 10740, Mexico. \\ ${ }^{3}$ University of the Basque Country (UPV/EHU), FAEII and BiRTE, 48015, Bilbao, Spain. \\ ${ }^{4}$ Universidade de Santiago de Compostela, Santiago de Compostela,15782, Spain. \\ *jmrocha@uvigo.es \\ ${ }^{+}$all authors contributed equally to this work
}

\begin{abstract}
Climate warming is expected to increase the frequency and magnitude of extreme events in the mid to long term. Here, we combine a model of forest management with inter-country input-output tables to estimate the economic effect on the EU-28 and USA economies of changes in the output of the forestry and logging sectors due to extreme forest disturbance events. Given our model results, we estimate that the impact on the EU-28 economy will be equivalent to the value of wood damaged multiplied 3.32 fold [3.00-3.44]. We find that the economic cost of a global pan-European extreme event (a pulse of 450 M m3) could be 120.4 billion Euros in the EU-28 and and 1.7 billion in the USA (i.e. 0.926 and $0.015 \%$ of their respective GDPs). Finally, we explore how to design incentives to increase the economic resilience of the response of forestry and logging companies to expected future climate change. Using a heterogeneous companies model, we show that payments to landowners to conserve forest increase economic resilience.
\end{abstract}

\section{Introduction}

Forests cover approximately 215 million ha in Europe, i.e. $33 \%$ of total continental European land ${ }^{1}$. EU forested areas ${ }^{2}$ sustain a major timber industry ${ }^{3}$ which produces an average of 562 million $\mathrm{m} 3$ of wood products per annum and provides direct jobs and income for at least 3 million people ${ }^{1}$. However, despite their high ecological, economic and social value, forests are threatened by a wide variety of factors. Of particular importance are natural disturbances such as fire, wind and bark beetles, which have affected approximately 35 million $\mathrm{m} 3$ of timber over the last 50 years ${ }^{4}$, i.e. an average of $0.15 \%$ of the total standing volume of Europees forests per year and $8.1 \%$ of the total annual area felled by EU countries ${ }^{4}$.

Climate change exacerbates the effects of these disturbances, and has major economic effects. Extreme events such as storms, droughts, flooding, and heat waves are probably the biggest threats in temperate oceanic regions ${ }^{5}$. In Europe, climate

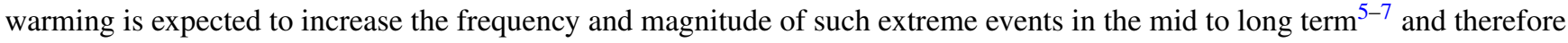
the impacts of forest disturbances.

Here, we assess the economic consequences of the occurrence of extreme fire, wind, and bark beetle event scenarios. We show that, given that forest companies use capital, labor, and intermediate inputs to harvest trees, the quantitative economic impact of natural disturbances is substantially amplified. In this framework, the economic impact of natural disturbances is not only the expected value of wood damaged, but also the reduction in wages and capital gains due to the decline in forest size. Given the results of our model, the economic losses of the forestry sector are equal to 2.25 [2.00 - 2.50] times the value of the wood damaged. Furthermore, the reduction in the output of the forestry sector also reduces its expenditures on other sectors, generating spillovers for the EU-28 economy. Under the scenario applied, those spillovers represent a further 0.69-1.10. Overall, the impact on the EU-28 economy is equivalent to the value of wood damaged multiplied 3.32 fold [3.00-3.44].

Finally, we build extreme disturbance event scenarios. We find that the economic cost of a global extreme event (a pulse equivalent to the 2010 annual roundwood output of 450 million m3) may be 120.4 billion Euros for the EU-28 and 1.7 billion for the USA. (i.e. 0.926 and $0.015 \%$ of their respective GDPs). 


\begin{tabular}{lrrr}
\hline & \multicolumn{3}{c}{ Impact at time of disturbance $t=0$} \\
\hline & $\inf ($ lower 10\%) & Median & sup (upper90\%) \\
\cline { 2 - 4 }$\Delta$ Forestry Output $_{0}$ & -0.7406 & -0.8326 & -0.9292 \\
$\Delta$ Wood damaged $_{0}$ & \multicolumn{3}{c}{1.0000} \\
\hline Impact multiplier & \multicolumn{3}{c}{ Cumulative $T=50, i=0.02$} \\
\hline & inf (lower 10\%) & Median & sup (upper90\%) \\
\cline { 2 - 4 } & -13.4144 & -15.0807 & -16.8327 \\
$\sum_{t=0}^{T}(1+i)^{-t} \Delta$ Forestry Output $_{t}$ & & \multirow{2}{*}{6.7164} \\
$\sum_{t=0}^{T} \Delta$ Wood damaged $_{t}$ & & -2.2454 \\
Cumulative multiplier(50) & -1.9973 & -2.5062 \\
\hline
\end{tabular}

Table 1. EU disturbance multipliers: average of the median and confidence intervals [ $10 \%$ and $90 \%$ of the posterior distribution] of the 17 IRFs estimated (Austria, Switzerland, Poland, Czechoslovakia, Hungary, Finland, Norway, Sweden, Denmark, France, Germany and Netherlands, United Kingdom, Ireland, Spain, Portugal and Italy).

\section{Results}

\section{Amplification: Impact on Forestry Output: Disturbance multipliers}

The impact of natural disturbances (wildfires, wind, storms, and/or insect outbreaks) on output depends on how each disturbance affects the quantities of capital and labor used by forestry companies to harvest trees.

If forestry companies do no react to (expected) future changes in forest size (wood disturbed reducing age-class [45-50] in the next 50 years), the change in output is proportional to the change in age-class [45-50] over the recovery period, i.e. with a constant harvest rate $\Delta(\%)$ Wood damaged is equal to the $\sum_{t=0}^{T} \Delta(\%)$ Forestry Output $t_{t}$.

However, the model estimated shows that companies change their harvest rates after a disturbance. To mitigate the impact of disturbances on forest owner companies, they increase their forest harvest rate (by reducing labor and capital proportionally by less than the reduction in forest size due to the disturbance). In other words the impact disturbance multiplier

$$
\text { Impact multiplier }=\frac{\Delta \text { Forestry Output }_{t=0}}{\Delta \text { Wood damaged }_{t=0}},
$$

(which measures the impact at the time when the disturbance occurs) is lower than one. Increasing the harvesting rate at the time of the disturbance delays the rate of forest recovery (the Impulse-Response Functions, IRF, of the forest size is lower than the IRF of newborn trees). That is, companies smooth the loss of wealth arising from the natural disaster over the 50 years needed for the full recovery of the forest, amplifying its economic impact. We use the cumulative disturbance multiplier

$$
\text { Cumulative multiplier }=-\frac{\sum_{t=0}^{T}(1+i)^{-t} \Delta \text { Forestry Output }_{t}}{\sum_{t=0}^{T} \Delta \text { Wood damaged }_{t}},
$$

to measure the amplification factor (see Table 1). The impact of disturbances on (the net present value of) forestry output is equal to the value of wood damaged amplified by a factor of 2.25 [2.00 - 2.51].

\section{Impact on EU and US economies: Spillover multipliers}

International trade and interdependencies between sectors greatly influence the economic consequences of forest disturbances. We use FIGARO to estimate the spillover effect of changes in the output of the forestry and logging sector.

These spillovers affect the sectors linked via supply and demand to the forestry and logging sector, but also other national economies where those sectors are located. Data shows that the spillovers are higher in those countries where forestry uses more intermediate inputs (see figure 2). Note that economic integration has led to international production value chains, and therefore natural disturbances impact on sectors that may be located in countries far from the zone directly affected by them. 
A
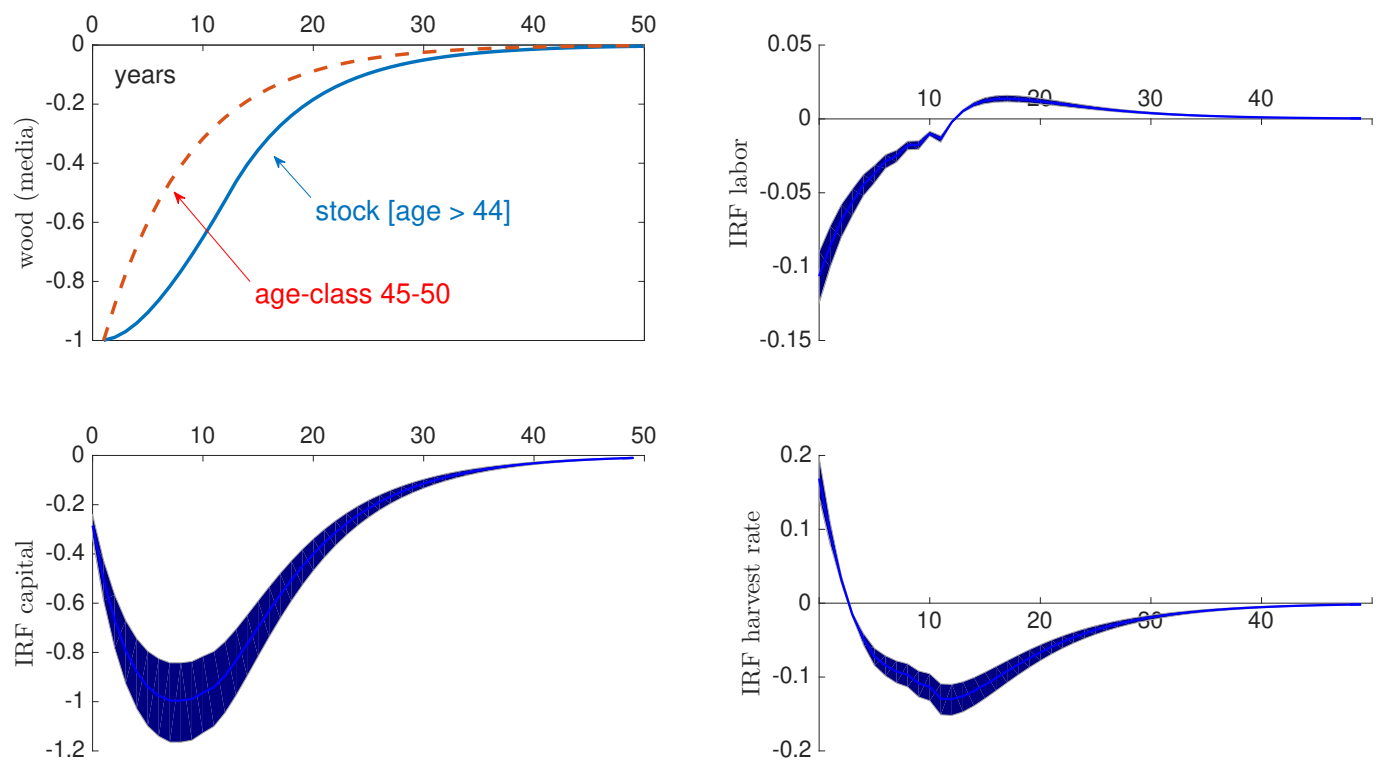

B

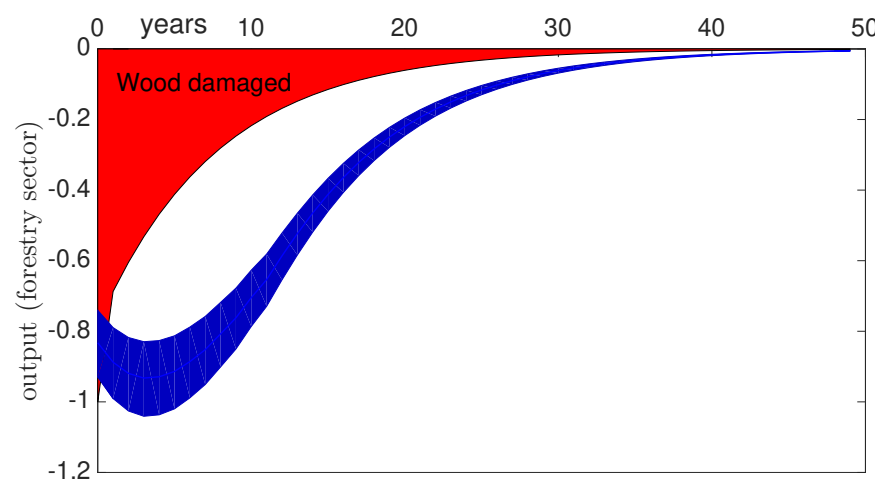

Figure 1. Impulse-Response Functions (IRF). Median and confidence intervals [ $10 \%$ an $90 \%$ of the posterior distribution] of forest size (top-left panel), labor (top-right panel), capital (bottom-left panel) and forest harvest rate (bottom-right panel). These functions show the reaction of the economy, i. e. the deviation with respect to the steady state in the absence of disturbances. Figure A: shows the IRF of age-class [45-50] and total wood stock size. As time goes on, newborn trees enable the forest to recover (in approximately 50 years). Note that in our model the total wood damaged is proportional to the area above age-class [45-50]. Figure B: The $y$ axis shows the value of the multiplier for each year t: In year 0 the IRF figures correspond to the impact multiplier. The change in output, $\Delta$ Forestry Output ${ }_{t}$, corresponds to the area above the IRF from $t=0$ to year $\mathrm{T}$. The $\Delta$ Wood damaged corresponds to the red area. 
A

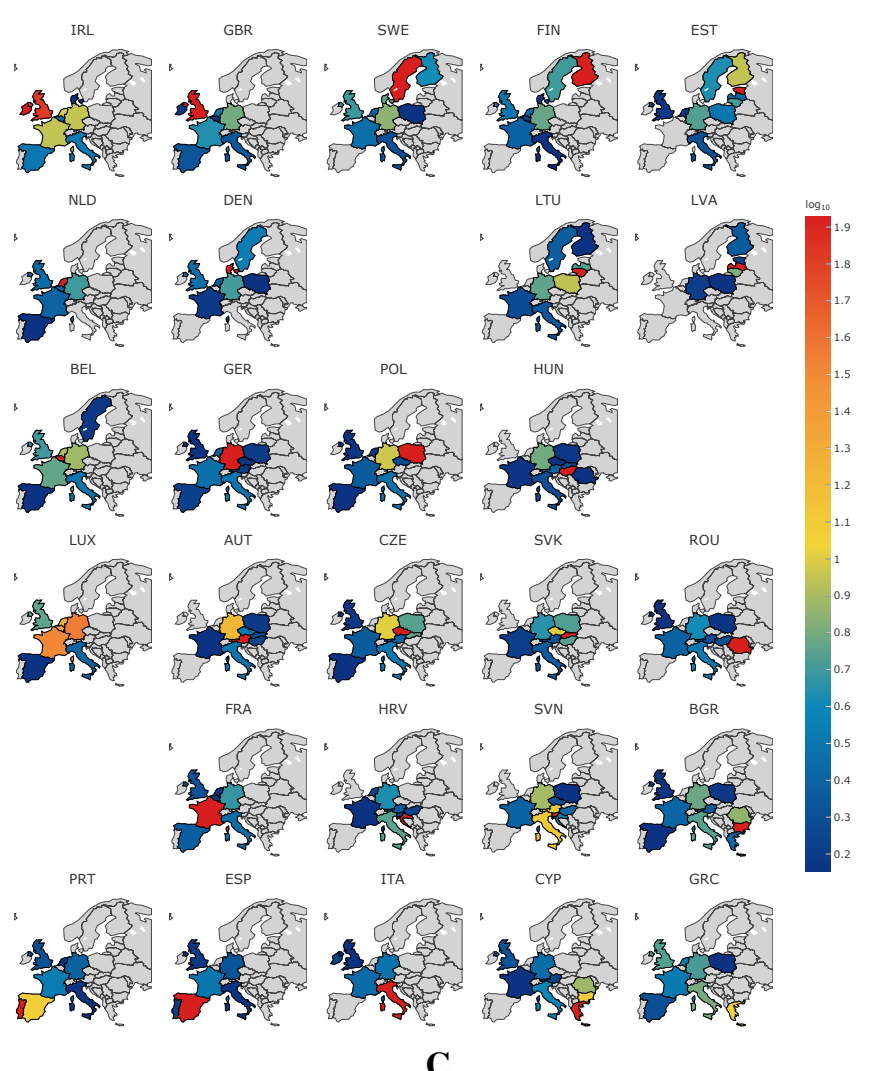

C

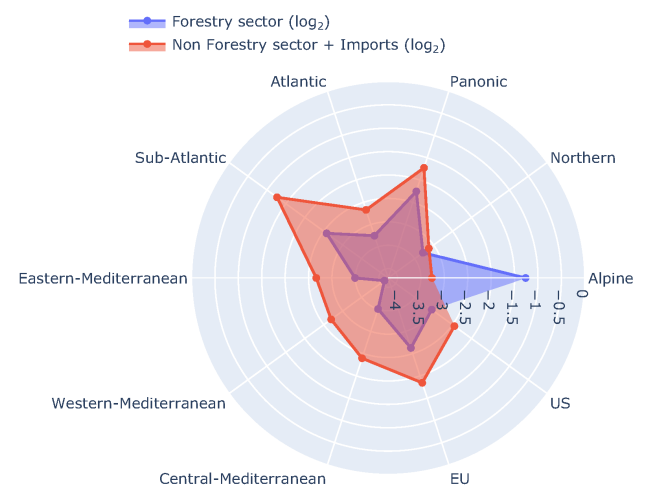

B
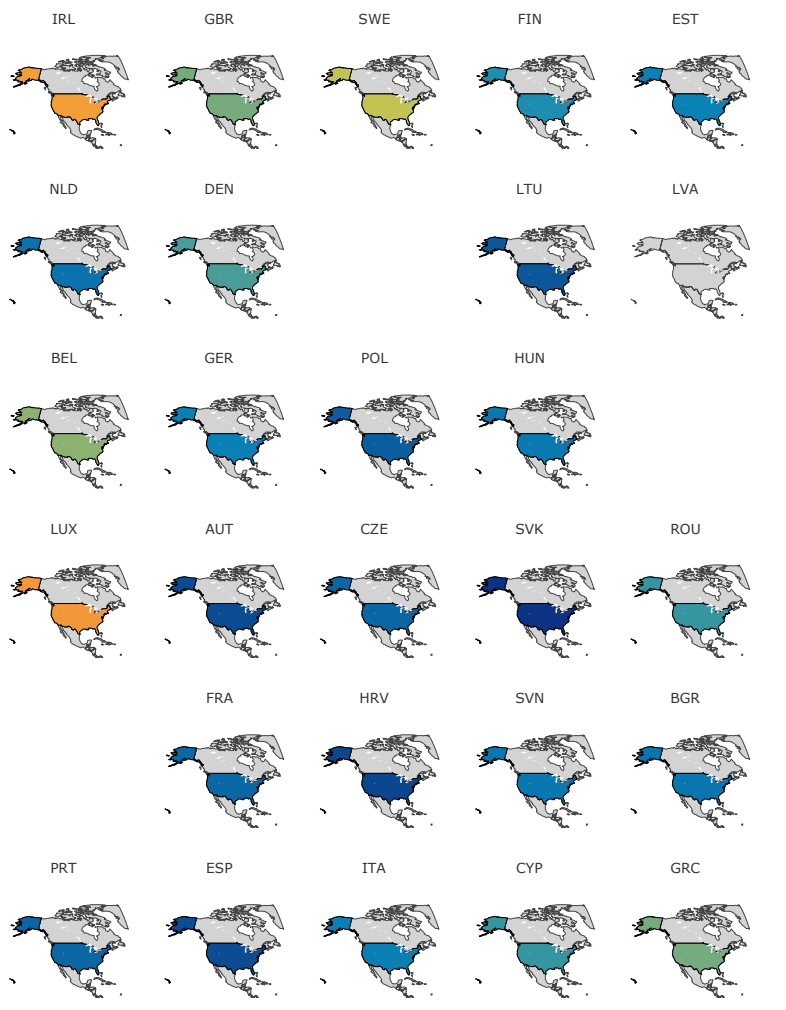

BGR

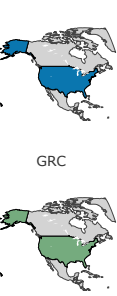

D

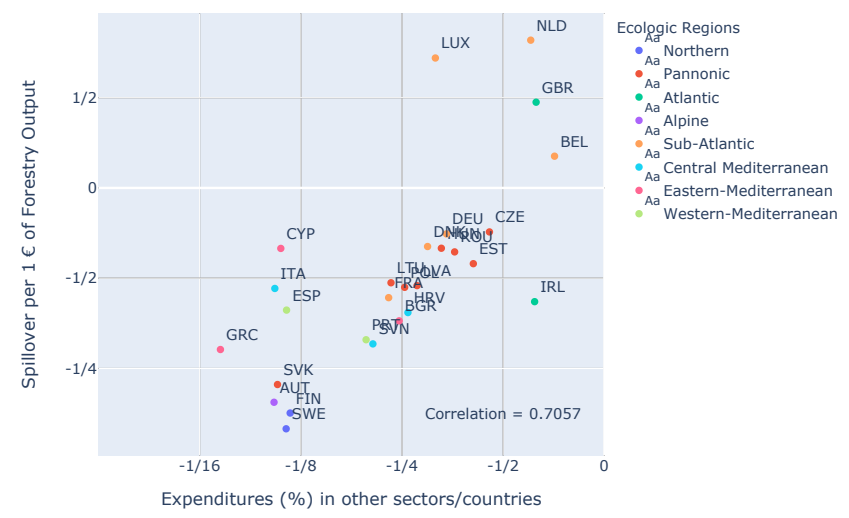

Figure 2. Input-output multipliers of the Forestry Sector. This figure shows the (log 10) impact on the outputs of the EU-28 (A) and USA (B) of a $€ 1$ reduction in the output of forestry and logging products for each EU country. The radar-plot $(\mathbf{C})$ shows the (average) expenditures on forestry products, logging and related services (A02, FIGARO) for each $e$ produced. The XY plot (D) shows that the Spillover impact is positively correlated with the size of expenditures from forestry output in other sectors/countries.

On average, the input-output multiplier amplifies the reduction in the forestry expenditures on intermediate inputs (induced by the disturbance) by a factor of 1.9 [1.73-2.03]. For instance the impact of a $€ 1$ reduction in the output of the EU-28 forestry and logging sector (proportionally to the relative weight of each country in the total forestry and logging sector of the EU) and logging sectors reduces output in the USA economy by around 4 percent. Moreover, countries which account for smaller proportions of total EU forestry output, such as the UK, experience high spillover effects. This is due to the structure of the 


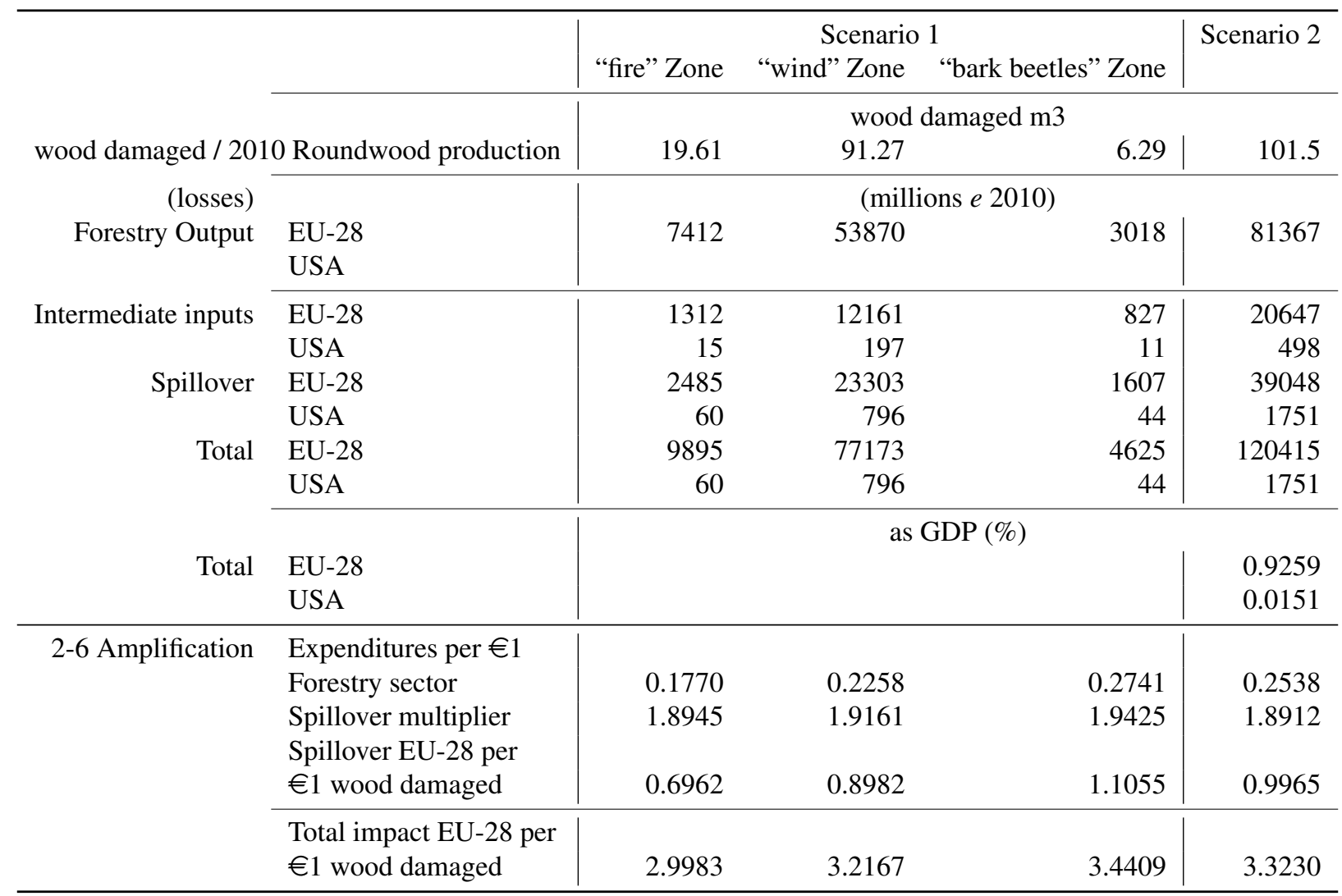

Table 2. Economic consequences of extreme events.

intermediate input expenditures from EU forestry output. For instance, 30\% of total expenditure is related to services (wholesale trade services, repair and installation services for machinery, transport services and financial services, etc (see Supplementary Table 1).

\section{Economic impact of extreme disturbances regimes}

Here, we build four scenarios to assess the impact of extreme events on the EU-28 economy. To explore how the impact depends on the damaged area, we use the geographical damage distribution. In the first three local scenarios we thus simulate the impact of the maximum reported national disturbed timber volume damaged from 1960 to 2005 for fire (SC1: "fire" Zone), wind (SC1: "wind" Zone), and bark beetles (SC1: "bark beetles" Zone). In developing the scenarios we only consider the subset of countries where the maximum damage is significant for each agent. Note that the scenarios are not similar in terms of size (see Supplementary Table 2).

We also build up a global scenario (SC2: EU-28) to assess the impact of incidence of a simultaneous pan-European scale extreme event. SC2 is built up as the sum of the wood damaged in SC1. This scenario involves the destruction of 382.7 million $\mathrm{m} 3$, which is $101.5 \%$ of the total amount of roundwood produced in Europe in 2010. Throughout SC2, for countries where disturbance data was not available on SC1 damage is assigned as $101.5 \%$ of the national roundwood output in 2010 (see Supplementary Table 2).

We use the cumulative multiplier together with the input-output methods to estimate the impact of forest disturbances on the EU-28 and USA economies. Table 2 shows the scale of the economic looses (in millions of $e$ 2010) of the extreme event considered in each scenario.

The reduction in forestry output generates spillovers for the EU economy which, under the scenario applied, account for a further 0.69 to 1.10 percent on top of the figure for the cumulative multiplier. Overall, the impact on the total output of the EU economy multiplies the value of damaged wood 3.32-fold [3.00-3.44].

Figures 3 shows that the amplification effect is not homogeneous across scenarios or zones. The heterogeneity observed suggests that the make-up of final goods (how domestic goods are combined with other domestic goods) and international value chains (how domestic goods are combined with foreign goods) of national forestry sectors is a key element in understanding the economic consequences of unexpected extreme events. 
A: Wood damaged (country share)
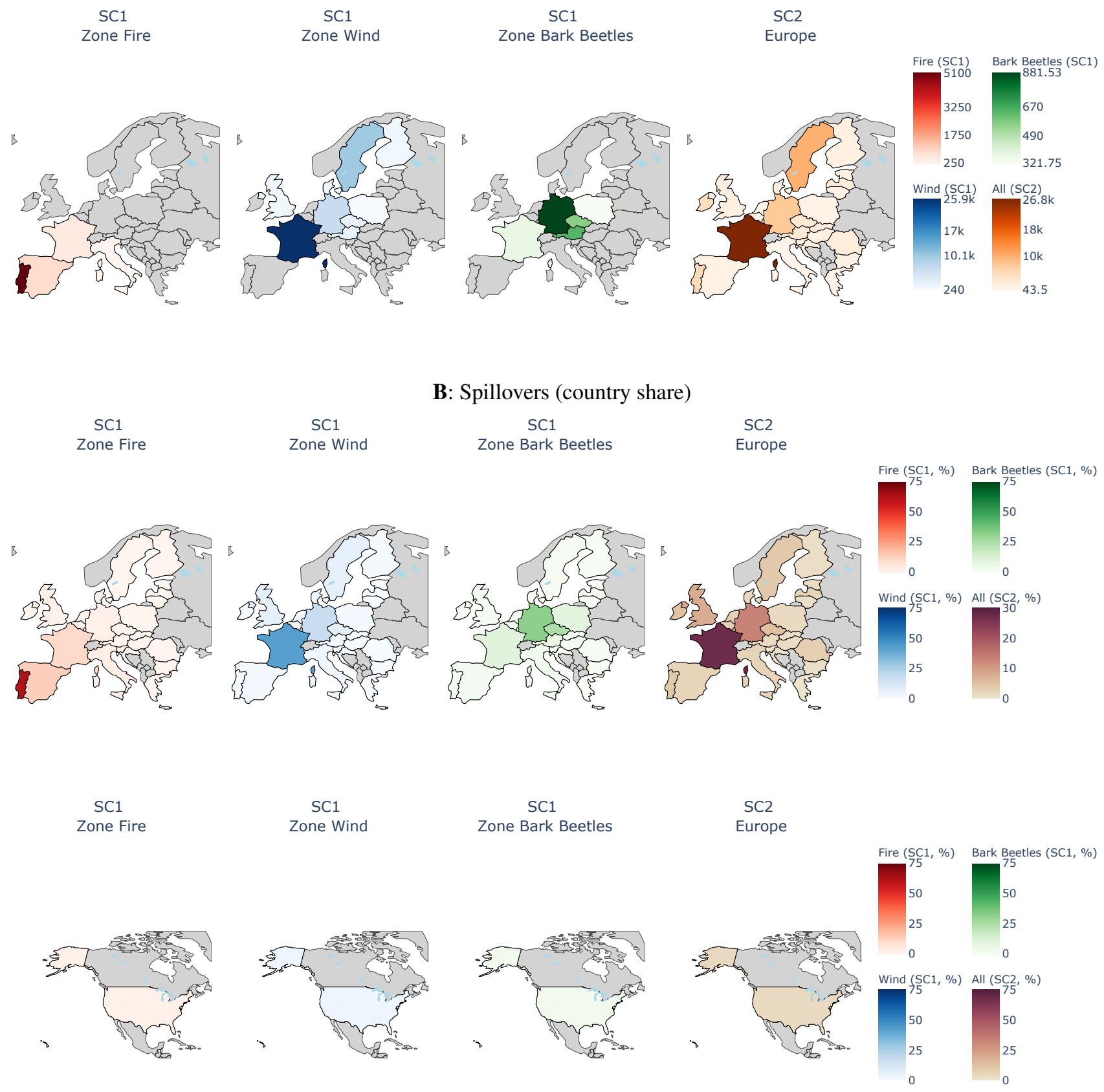

Figure 3. Wood damaged, country share (A) and Spillovers (B) in each Scenario. (see Supplementary Table 3).

\section{Discussion}

The use of an age-structured model and historical country maximum disturbance data means that we are probably underestimating the economic cost of forest disturbances. On one hand, in the model wood damaged is measured based on the future volume lost (opportunity cost). However, the data available uses the "current" volume of wood damaged, so our amplification results are conservative. More research on cut-off ages and volumes is needed to obtain a more reliable measure of amplification. On the other hand, our scenarios are based on historical country maximums. However ${ }^{5},{ }^{6},{ }^{7}$ show that in Europe global warming is expected to increase the frequency, magnitude and therefore impact of forest disturbances in the medium and long term. For 
A

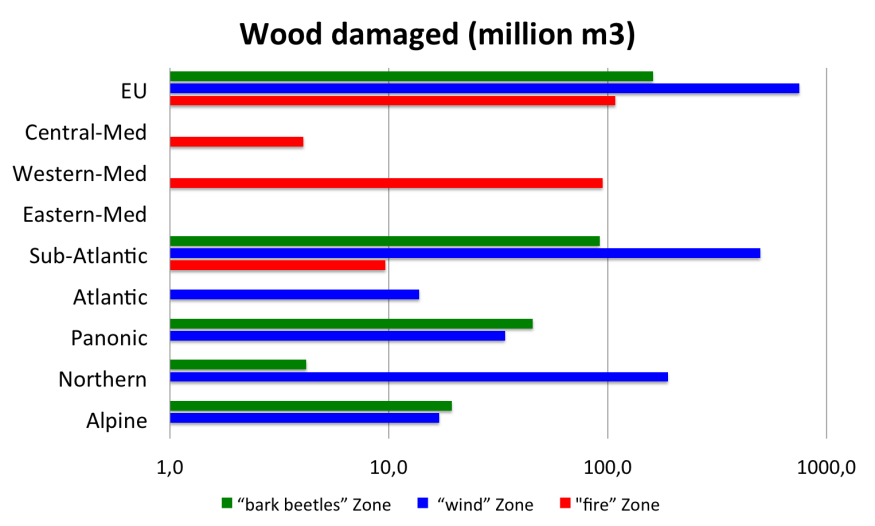

B

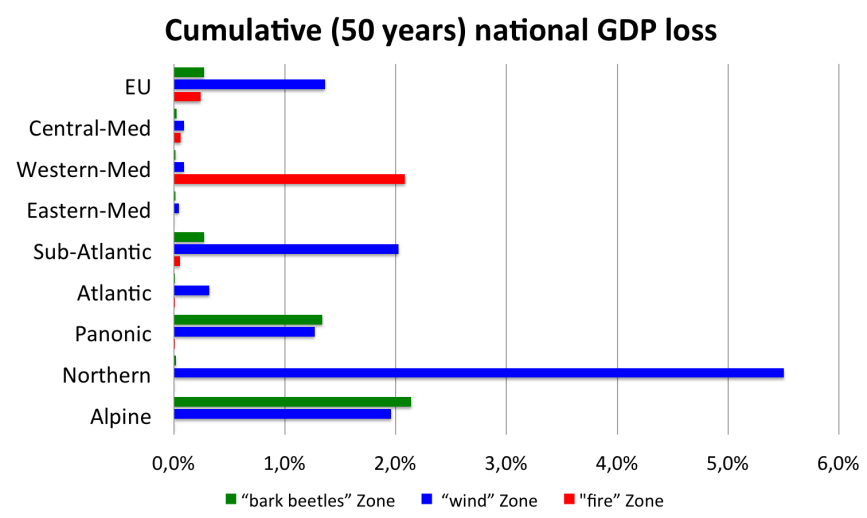

Figure 4. Economic consequences of extreme events. Impact by Ecological zones: Alpine: Austria; Atlantic: United Kingdom and Ireland; Central-Mediterranean: Croatia, Italy and Slovenia; Eastern-Mediterranean: Bulgaria, Cyprus, Greece and Malta; Northern: Finland and Sweden; Panonic:, Estonia, Hungary, Lithuania, Latvia, Poland, Romania and Slovak Republic; Sub-Atlantic: Belgium, Germany, Denmark, France, Luxembourg and Netherlands; Western-Mediterranean: Spain and Portugal. (see Supplementary Table 4)

instance, ${ }^{8}$ calculate that in 2021-2030 there will be losses of $11.7 \mathrm{M} \mathrm{m} 3 /$ year from fire, $44.5 \mathrm{M} \mathrm{m} 3 /$ year from wind, and $17.9 \mathrm{M}$ $\mathrm{m} 3 /$ year from bark beetle. That would mean (average) losses per annum of $e 3.36,10.50$ and 5.45 billion respectively and a possible total of $0.15 \%$ of the EU-28 GDP. Note that our extreme global pan-European scenario is less than seven times this yearly average.

Given these high economic costs of forest disturbances, measures need to be taken to mitigate their effects. A scheme of payments to landowners (SPL) my be successful in protecting biodiversity as it leads to an ex-post faster recovery once a disturbance has happened $\left(\mathrm{see}^{9-11}\right)$.

We use a model of heterogeneous landowners (see Resilience properties of SPL at supplementary information) affected by idiosyncratic disturbances to assess the resilience properties of incentive schemes based on paying landowners to conserve forests. On the basis of our model results, paying landowners to conserve forests reduces the vulnerability of forests to large, unexpected disturbances and, so such payments are an instrument conducive to the resilience of natural capital.

\section{Methods}

We calculate the impact of natural disturbances in forests (fire, wind, and bark beetles) on the EU-28's output in two steps. First, we estimate using bayesian methods a (general equilibrium) version of the harvesting problem solved by ${ }^{12}$ to quantify the intertemporal impact of natural disturbances on the output of the forestry and logging sector. The model is estimated using (i) 45 years disturbed timber volume time series; (ii) yearly national roundwood output data; (iii) forestry and logging labor (working hours) time series; and (iv) age-structure forest area time series for a sample of 19 EU countries (see A recursive Harvesting Problem at supplementary information). Second, we calculate the spillover effects from the forestry and logging sector for EU-28 (and US) GDP using (EU) inter-country input-output tables as $\operatorname{per}^{13}$ (FIGARO). This database divides the industry into 64 activities and covers all EU Member States (EU-28) plus the USA (see Input-Output analysis at supplementary information).

\section{References}

1. EFI \& Unece, F. State of europe's forests 2015 (2015).

2. Böttcher, H., Verkerk, P. J., Gusti, M., HavlÍk, P. \& Grassi, G. Projection of the future eu forest co 2 sink as affected by recent bioenergy policies using two advanced forest management models. Gcb Bioenergy 4, 773-783 (2012).

3. Hanewinkel, M., Cullmann, D. A., Schelhaas, M.-J., Nabuurs, G.-J. \& Zimmermann, N. E. Climate change may cause severe loss in the economic value of european forest land. Nat. climate change 3, 203-207 (2013).

4. Schelhaas, M.-J., Nabuurs, G.-J. \& Schuck, A. Natural disturbances in the european forests in the 19th and 20th centuries. Glob. Chang. Biol. 9, 1620-1633 (2003). 
5. Lindner, M. et al. Climate change impacts, adaptive capacity, and vulnerability of european forest ecosystems. For. ecology management 259, 698-709 (2010).

6. Bolte, A. et al. Adaptive forest management in central europe: climate change impacts, strategies and integrative concept. Scand. J. For. Res. 24, 473-482 (2009).

7. Morin, X. et al. Long-term response of forest productivity to climate change is mostly driven by change in tree species composition. Scentific Reports 8, 5627- (2018).

8. Seidl, R., Schelhaas, M.-J., Rammer, W. \& Verkerk, P. J. Increasing forest disturbances in europe and their impact on carbon storage. Nat. climate change 4, 806-810 (2014).

9. Muñoz-Piña, C., Guevara, A., Torres, J. M. \& Braña, J. Paying for the hydrological services of Mexico's forests: Analysis, negotiations and results. Ecol. Econ. 65, 725-736 (2008).

10. Banks-Leite, C. et al. Using ecological thresholds to evaluate the costs and benefits of set-asides in a biodiversity hotspot. Science 345, 1041-1045, DOI: 10.1126/science.1255768 (2014).

11. Alix-Garcia, J., Shapiro, E. \& Sims, K. Forest conservation and slippage: Evidence from mexico's national payments for ecosystem services program. Land Econ. 88, 613-638, DOI: 10.3368/le.88.4.613 (2012).

12. Reed, W. J. The effects of the risk of fire on the optimal rotation of a forest. J. environmental economics management 11, 180-190 (1984).

13. Remond-Tiedrez, I. et al. European Union inter-country supply, use and input-output tables a Full international and global accounts for research in input-output analysis (FIGARO) (European Commission, 2019).

For data citations of datasets uploaded to e.g. figshare, please use the howpublished option in the bib entry to specify the platform and the link, as in the Hao:gidmaps:2014 example in the sample bibliography file.

\section{Acknowledgements}

For providing damaged data and helpful comments we thank Rupert Seidl and Juha Honkaniemi. Da-Rocha, García-Cutrín, Gutiérrez and Sánchez acknowledge financial support from the Spanish Ministry of the Economy, Industry and Competitiveness (REFORCE, project PCIN-2017-054 and ECO2016-78819-R, AEI/ERDE, EU). Da-Rocha, García-Cutrín and Sánchez also acknowledge financial support from Xunta de Galicia (ED431B 2019/34) and Gutiérrez from the Basque Government (BiRTE, IT-1336-19). Sempere acknowledges financial support from CONACyT (project No. A1-S-11222).

\section{Author contributions statement}

All author contributed (computing and analysing results) equally to this work and reviewed the manuscript.

\section{Additional information}

DYNARE codes (and data) for IRF estimation and matlab codes for computing spillovers are available by request.

\section{Competing interests}

The author(s) declare no competing interests. 
A
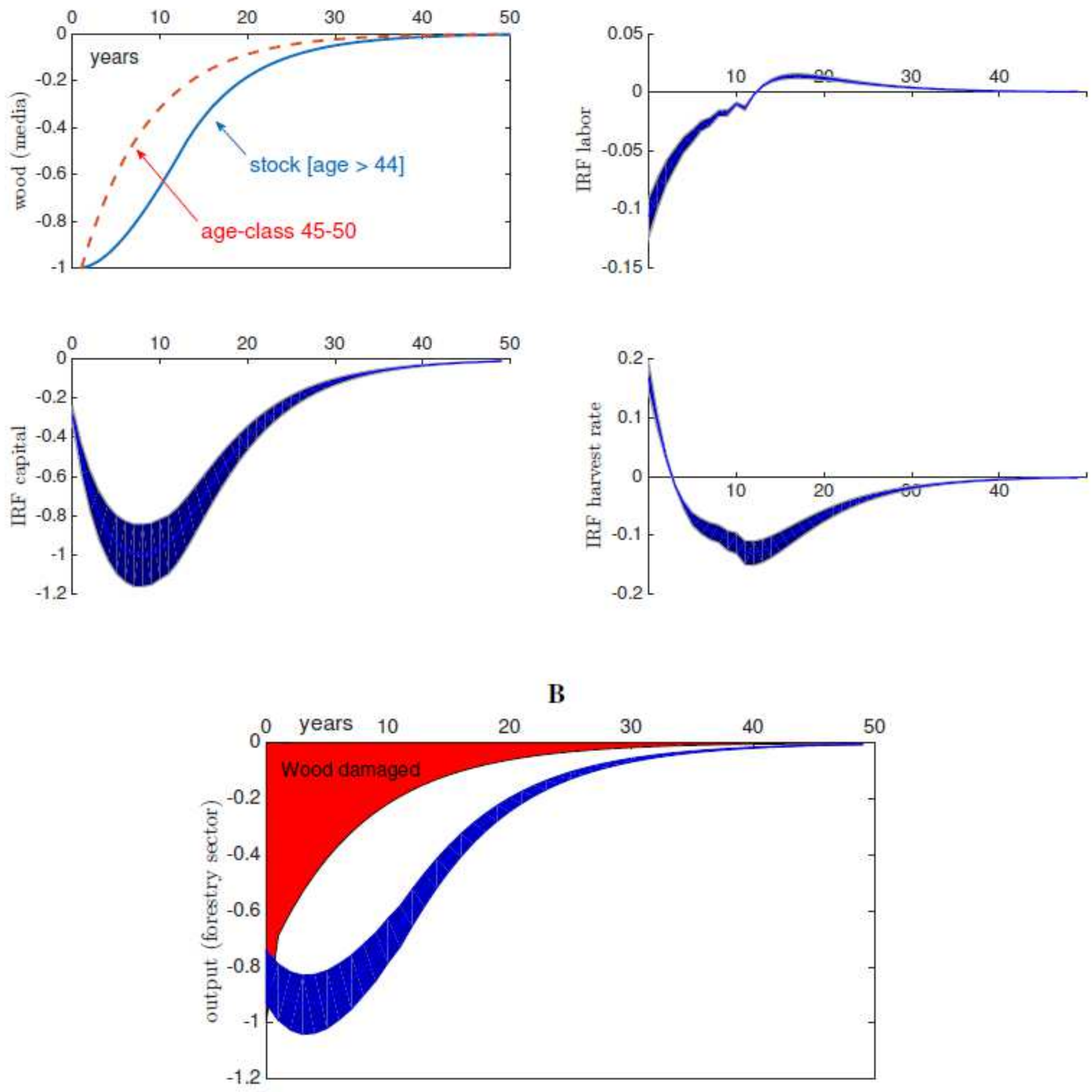

\section{Figure 1}

Impulse-Response Functions (IRF). Median and confidence intervals [10\% an $90 \%$ of the posterior distribution] of forest size (top-left panel), labor (top-right panel), capital (bottom-left panel) and forest harvest rate (bottom-right panel). These functions show the reaction of the economy, i. e. the deviation 
with respect to the steady state in the absence of disturbances. Figure A: shows the IRF of age-class [4550] and total wood stock size. As time goes on, newborn trees enable the forest to recover (in approximately 50 years). Note that in our model the total wood damaged is proportional to the area above age-class [45-50]. Figure $\mathrm{B}$ : The $\mathrm{y}$ axis shows the value of the multiplier for each year $\mathrm{t}$ : In year 0 the IRF figures correspond to the impact multiplier. The change in output, $\Delta$ Forestry Outputt, corresponds to the area above the IRF from $t=0$ to year $\mathrm{T}$. The $\Delta$ Wood damaged corresponds to the red area.

A
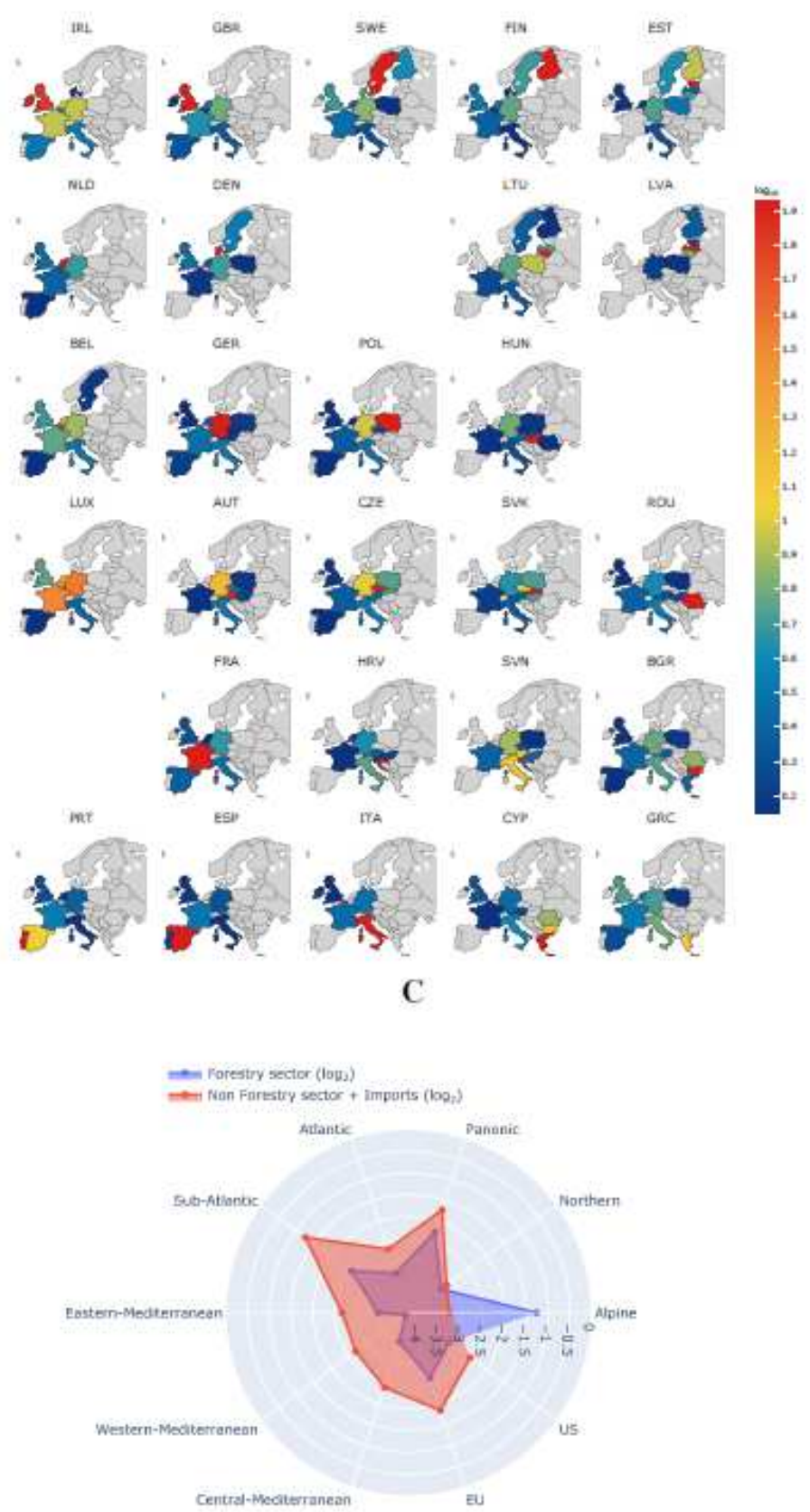

B
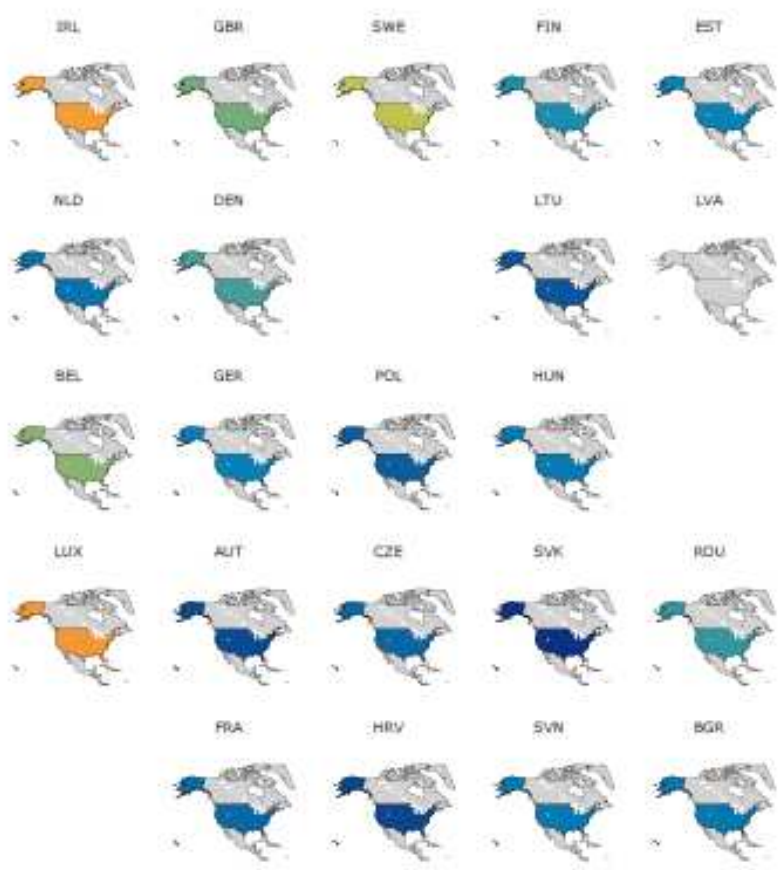

esp

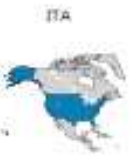

$c r$
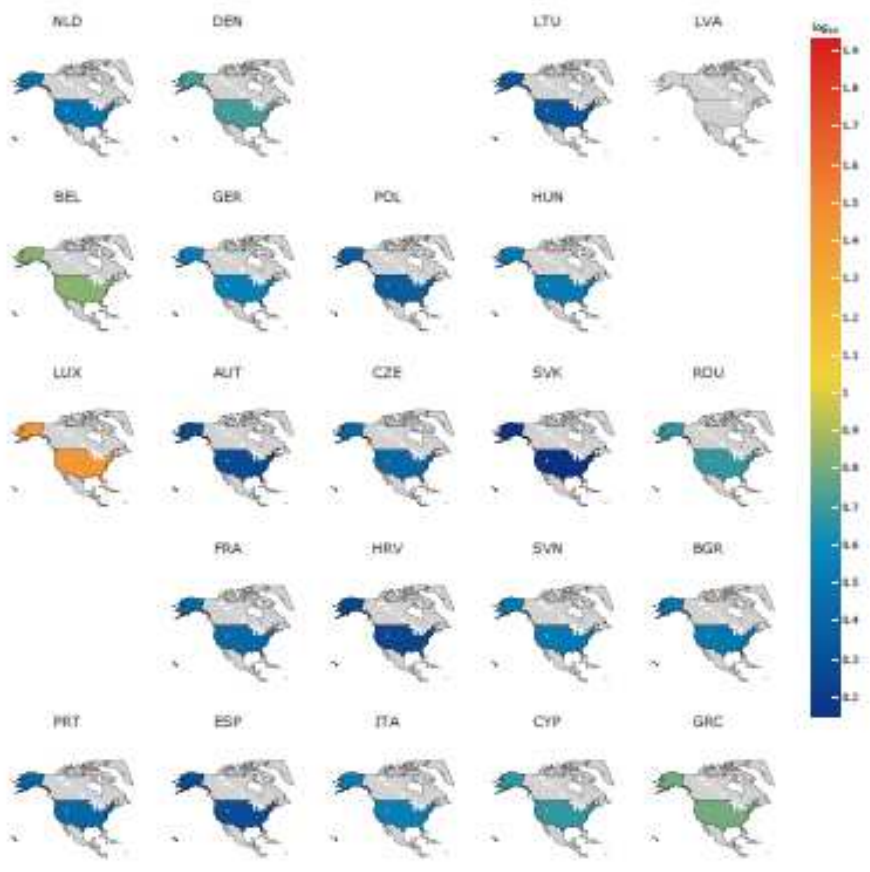

anc

D

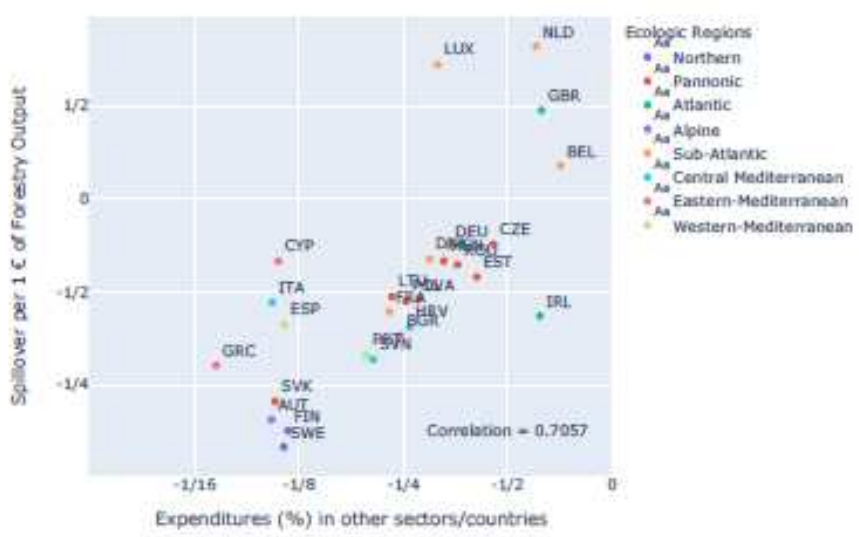

Figure 2 
Input-output multipliers of the Forestry Sector. This figure shows the $(\log 10)$ impact on the outputs of the EU-28 (A) and USA (B) of a e1 reduction in the output of forestry and logging products for each EU country. The radar-plot (C) shows the (average) expenditures on forestry products, logging and related services (A02, FIGARO) for each e produced. The XY plot (D) shows that the Spillover impact is positively correlated with the size of expenditures from forestry output in other sectors/countries.

A: Wood damaged (country share)
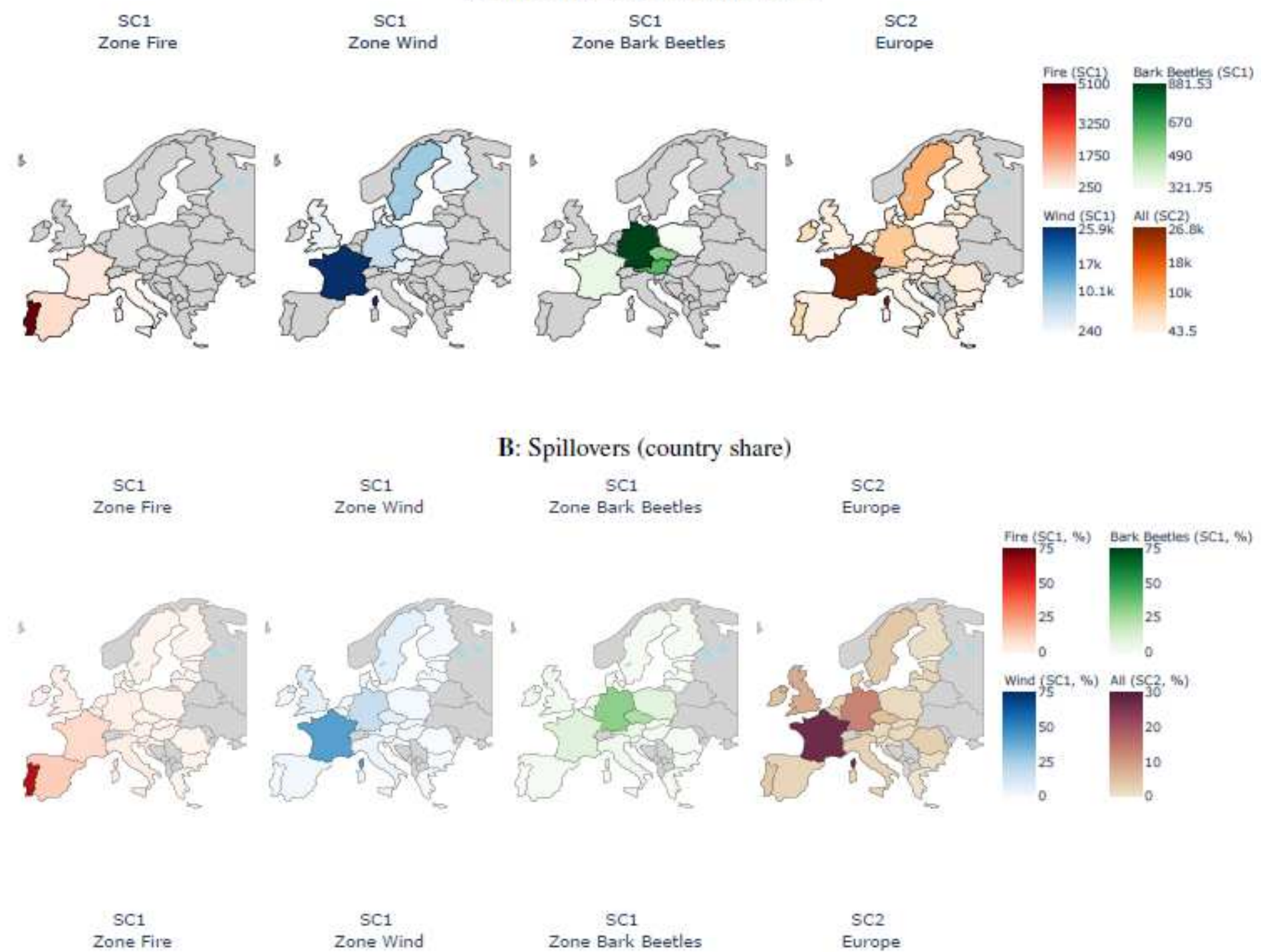

B: Spillovers (country share)
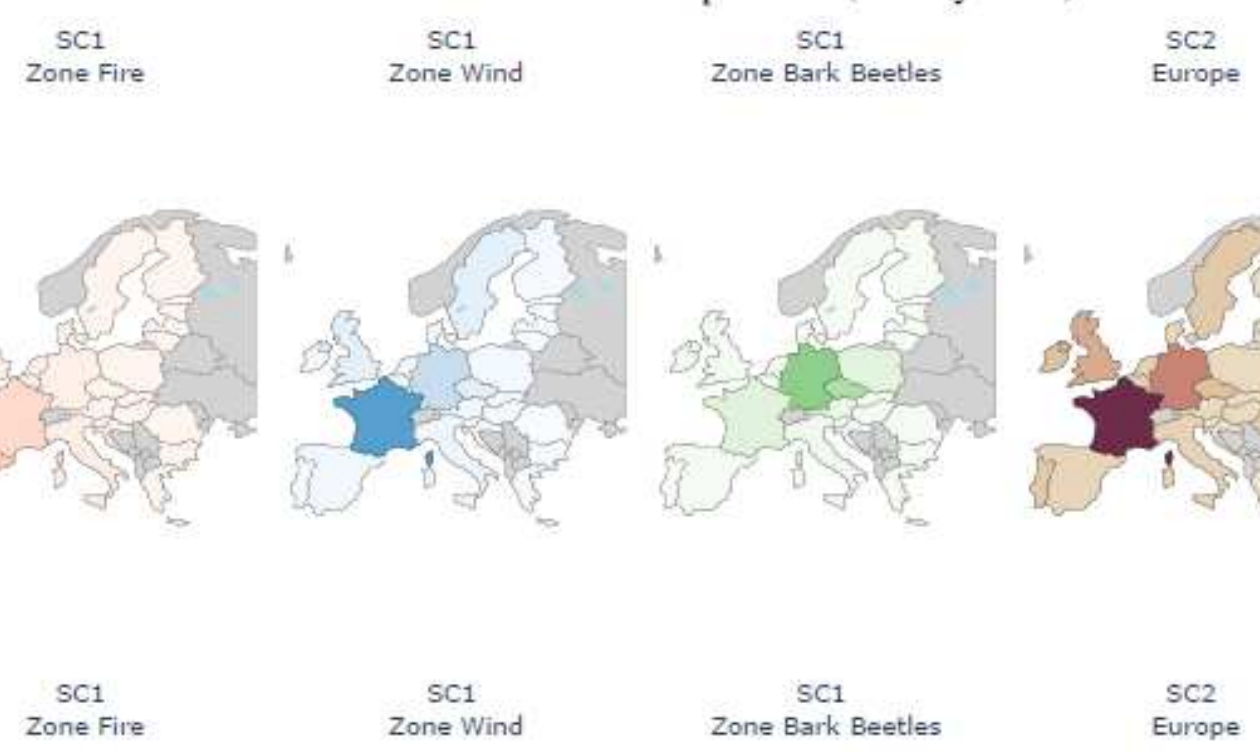

$\mathrm{SC} 2$

zone Fire

Zone Wind

Zone Bark Beetles
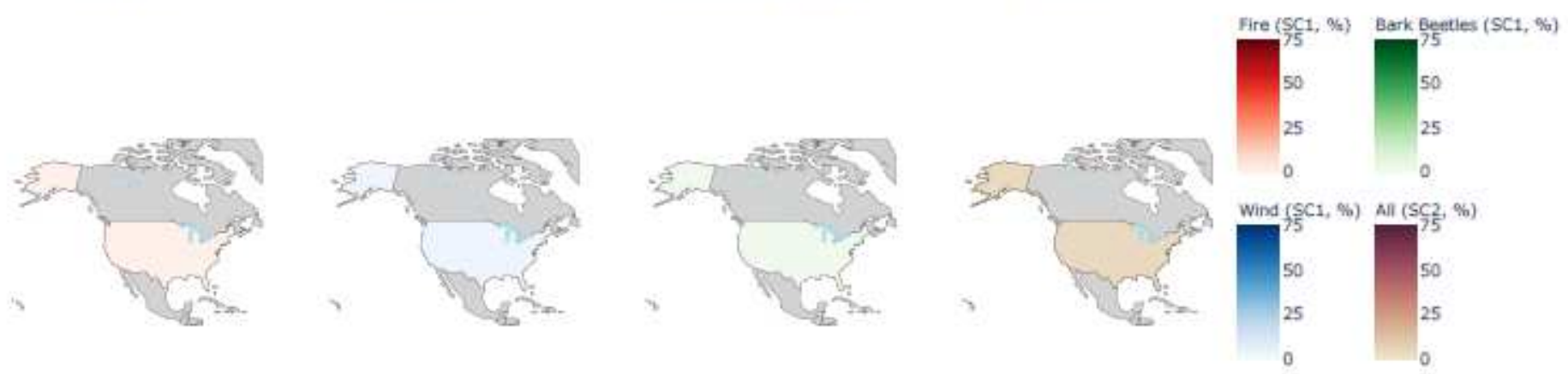

Figure 3 
Wood damaged, country share (A) and Spillovers (B) in each Scenario. (see Supplementary Table 3).

A

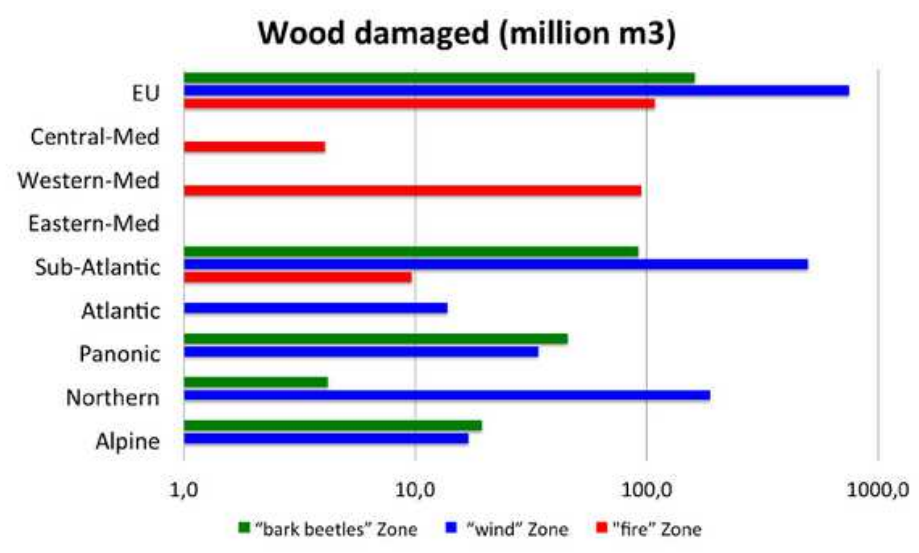

B

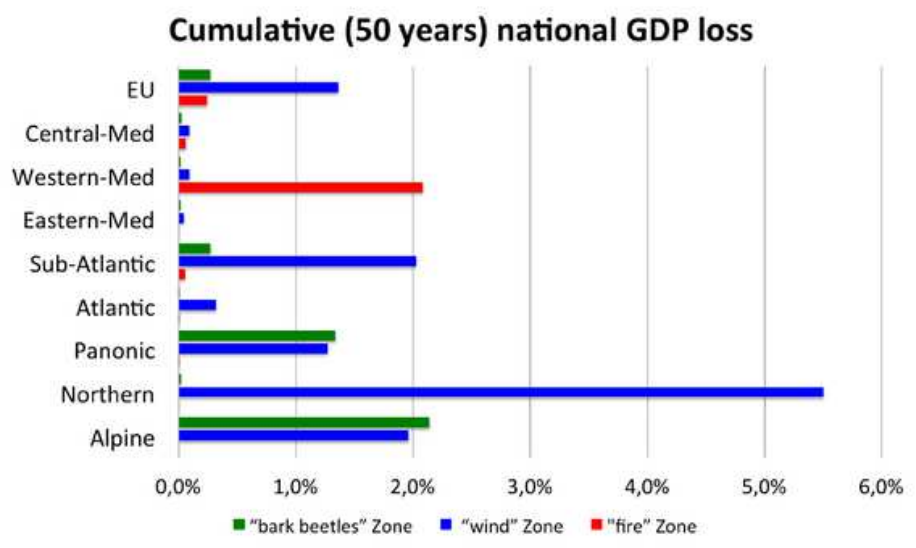

\section{Figure 4}

Economic consequences of extreme events. Impact by Ecological zones: Alpine: Austria; Atlantic: United Kingdom and Ireland; Central-Mediterranean: Croatia, Italy and Slovenia; Eastern-Mediterranean: Bulgaria, Cyprus, Greece and Malta; Northern: Finland and Sweden; Panonic:, Estonia, Hungary, Lithuania, Latvia, Poland, Romania and Slovak Republic; Sub-Atlantic: Belgium, Germany, Denmark, France, Luxembourg and Netherlands; Western-Mediterranean: Spain and Portugal. (see Supplementary Table 4)

\section{Supplementary Files}

This is a list of supplementary files associated with this preprint. Click to download.

- SuppInfEcolossesofForestDIsturbances.pdf 